\title{
Natural hydraulic lime mortars: influence of the aggregates
}

\author{
Faria $P^{1}$, , Silva V. ${ }^{2}$ \\ 1. NOVA University of Lisbon, Dep. Civil Eng., paulina.faria@fct.unl.pt \\ 2. NOVA University of Lisbon, Dep. Civil Eng.,vmd.silva@fct.unl.pt
}

\begin{abstract}
Natural hydraulic lime specifications changed with the new version of standard EN 459-1: 2010 and a new Portuguese NHL3.5 appeared in the market. The characteristics of mortars depend on many different parameters such as the type of binder, the type of aggregates, the use of fillers and of superplasticizers; also on mixing and curing conditions. In this paper NHL3.5 mortars with binder:aggregate volumetric proportions 1:3 were prepared, varying the aggregates type and proportions between them. Two coarse sands, a medium sand, a river sand, a finer sand, a calcareous filler and a ceramic powder were used. The two last mentioned aggregates were byproducts from industry. Prismatic mortar samples and samples of mortar applied over brick were prepared and conditioned in two different situations - following standard EN 1015-11 and at 65\% relative humidity with initial daily water spray. Mortars were characterized in the fresh state and at the age of 28 days. Results showed the influence namely of the curing, particularly in terms of water capillary, of the superplasticizer and of the fillers. They also showed that NHL3.5 mortars seem to be adequate for old masonries conservation and repair and, in some situations, they can be an alternative to air lime based mortars.
\end{abstract}

Keywords: natural hydraulic lime, aggregate, particle size, mortar, characterization

\section{Introduction}

Traditionally mortars were prepared in situ in working sites but actually, at least the dry constituents are often prepared industrially. In situ mortars must be simple, without many different constituents, so they can be easily reproduced from batch to batch. The industrial preparation of the dry constituents can facilitate the introduction of different ones, namely of admixtures, several binders, different types of aggregates and with different particle size distributions. It can also turn possible the addition of byproducts and industrial residues, which can contribute for the technical efficiency, sustainability and economy of the mortars.

Mortar aggregates are mainly sands but the type and particle size distribution of sands can be diverse and contribute to mortars characteristics. Residues can also be used as aggregates and fillers and alter the mortars microstructure.

The new version of standard EN 459-1:2010 (CEN 2010) redefined the specifications and characteristics of limes with hydraulic properties. Some of the previously named natural hydraulic limes (NHL), following EN 459-1:2001 (CEN 2001), are now classified as hydraulic lime HL as they contain additions. For that reason the characteristics previously presented for NHL mortars can no longer be extrapolated and compared to recent NHL mortars, due to great differences on the lime constitution, formulation and behaviour that can occur with these NHL binders. Problems of inconstancy of characteristics that were found in previous NHL (Charola 2005) should also be evaluated to see if, hopefully, they are no longer found.

A new Portuguese natural hydraulic lime NHL3.5 appeared in the market and has been widely used in Portugal and elsewhere; following EN 459-1:2010 (CEN 2010) it can not have any addition, have to present at least $25 \%$ of calcium hydroxide and a maximum of $2 \%$ of sulphates. Recent studies have shown that mortars with this lime can present a behaviour in terms of capillary suction and drying 
comparable to those of air-lime based mortars (Faria et al 2012, Grilo 2013), very different from previous NHL mortars. Those characteristics can contribute to a good behaviour particularly repair.

Within this context, this study began by trying to develop a mortar that could be used to enwrap a net to confine and reinforce old masonry walls and also to try to evaluate which aggregates to use for mortars to repoint stone masonry; at the same time an attempt was made to improve sustainable constructive practices.

Different mortars were formulated with this new NHL3.5 using various types of aggregates. Diverse mixtures of aggregates with different particle size distributions were also prepared. Fresh mortars were characterized in terms of composition, water/binder ratio, bulk density and flow table consistency. Samples were prepared applying the mortars in moulds but also directly over bricks, to reproduce the suction of the support on real applications, and maintained in two curing conditions.

The aim of this work is to present the characterization of these NHL3.5-based mortars and evaluate its compatibility to old masonry walls of existent buildings.

The evaluation of characteristics, particularly in terms of dynamic modulus of elasticity, flexural and compressive resistances, capillary water absorption, drying capacity and porosity (of the mortars applied on the moulds but also of the mortars applied over bricks to simulate the suction of the walls) will be discussed, mainly focusing the role of the different aggregates.

\section{Materials, mortars, samples and curing}

The binder used for the mortars preparation was a NHL3.5 produced by SECIL at a maximum temperature of around $900^{\circ} \mathrm{C}$ (information from the producer). Chemical characteristics, also provided by the producer, are presented in Table 1.

Table 1: Chemical characterization of NHL3.5.

\begin{tabular}{|c|c|c|c|c|c|c|c|c|c|c|c|c|c|c|}
\hline Materia & & & $\mathrm{SiO}$ & $\mathrm{Al}_{2} \mathrm{O}$ & $\mathbf{M g}$ & & $\mathrm{Fe}_{2} \mathrm{O}$ & $\mathbf{K}_{2}$ & TiO & $\mathrm{Na}_{2}$ & SrO & $\overline{\mathbf{P}_{2} \mathbf{O}}$ & Mn & \\
\hline 1 & $\mathrm{CaO}$ & $\mathrm{CO}_{2}$ & 2 & 3 & O & $\mathrm{SO}_{3}$ & 3 & O & 2 & O & 2 & 5 & O & Cl \\
\hline & 62,0 & 25,6 & & & & 1,2 & & & & & & & & 0,0 \\
\hline HL3.5 & 7 & 6 & 5,70 & 1,84 & 1,36 & 9 & 1,22 & 0,49 & 0,14 & 0,08 & 0,06 & 0,03 & 0,02 & 2 \\
\hline
\end{tabular}

The aggregates were: a current siliceous river sand $R$, a coarse siliceous washed sand $G$ and calcareous filler Fl; in one of the mortars a superplasticizer SP was used. A ceramic powder CP was also used in one of the mortars instead of the calcareous filler. One of the mortars was prepared with another coarse siliceous washed sand G2, a medium siliceous washed sand M and a finer siliceous washed sand F; this last mixture of aggregates have been used for experimental work within projects METACAL and LIMECONTECH, simulating an old mortar.

All the mortars were formulated with a volumetric proportion of 1:3 (binder: aggregate), with different aggregate mixtures (type and proportions between the aggregates) and are designated by the volumetric proportions of each aggregate. The particle size distributions of each of the aggregates and of the mixtures of aggregates of the mortars are presented in Figure 1.

The dry constituents were manually homogenised, the quantity of water to obtain mortars with good workability was added in the first seconds of mechanical mixing in a mechanical laboratory mixing equipment. The mixing went on for three minutes. Flow table consistency and bulk density were determinate for the fresh mortars, based on EN 1015-3 (CEN 1999) and EN 1015-6 (CEN 1998). Mortar designations, proportions, water/binder ratios, flow table consistency, bulk density and workability evaluation are presented in Table 2.

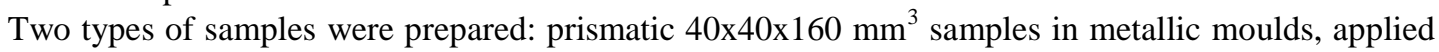
in two layers, each of one mechanically compacted with 20 strokes; $1.5 \mathrm{~cm}$ thickness of mortar over current hollowed ceramic bricks with $20 \times 30 \mathrm{~cm}^{2}$ surface. For the preparation of these samples, the bricks were previously sprayed with water and the mortar was dropped from a constant high of $70 \mathrm{~cm}$ to simulate a constant energy of application. The samples of mortar over bricks were only prepared with some of the mortars. Prismatic samples were held in two different curing conditions $\mathrm{N}$ and A, while brick samples were only conditioned at curing A. For standard curing N, samples were held inside the moulds involved in polyethylene until demoulding, at the second day of curing; kept involved in polyethylene 
until 7 days of age (high relative humidity ambiance) and, until the age required for the test, kept at standard laboratory conditions at $65 \pm 5 \% \mathrm{RH}$ and $20 \pm 2^{\circ} \mathrm{C}$ temperature, following EN 1015-11 (CEN 1999). For curing A samples were sprayed with water from the $2^{\text {nd }}$ to the $5^{\text {th }}$ day of age, demoulded at the age of 2 days and also held at $65 \% \mathrm{RH}$ and $20^{\circ} \mathrm{C}$ until the age required for the test. In Figure 2 curing conditions of different samples and curing stages can be observed.
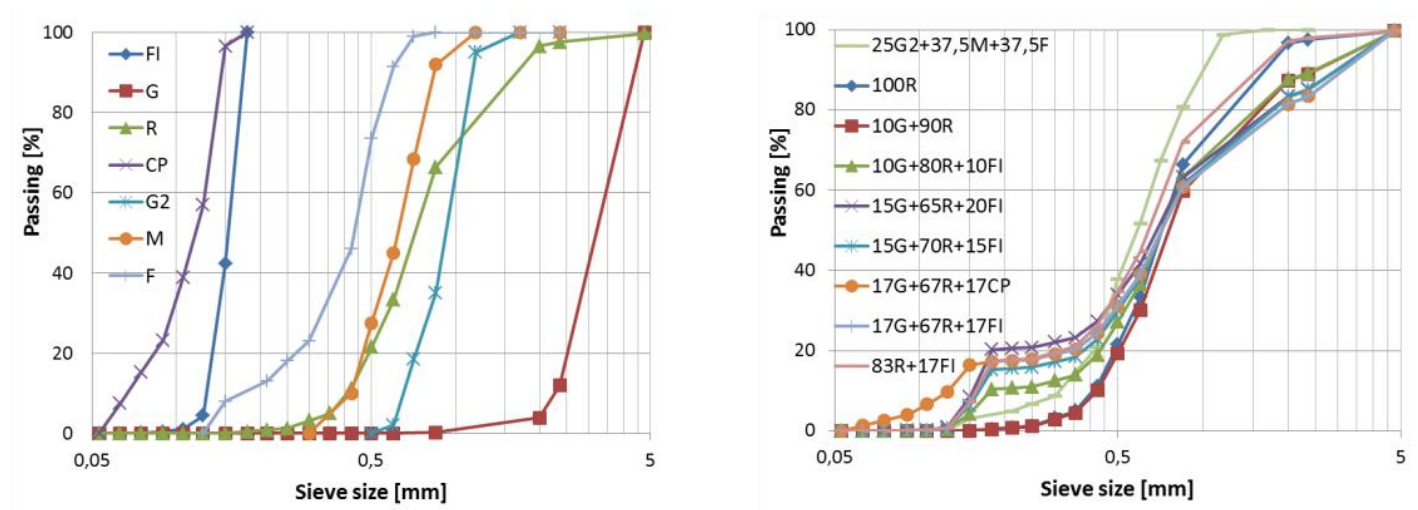

Figure 1: Particle size distribution of each aggregate and of the mixtures of aggregates in the mortars.

Table 2: Mortar designation, proportion, water/binder ratio (W/B), flow table consistency, bulk density (BD) and workability evaluation.

\begin{tabular}{|c|c|c|c|c|c|c|c|c|}
\hline Mortar & & $\begin{array}{l}\text { Volumetric } \\
\text { Proportion } \\
\end{array}$ & Weigh & ht Proportion & $\begin{array}{c}\mathrm{W} / \mathrm{B} \\
{[-]} \\
\end{array}$ & $\begin{array}{c}\text { Consist } \\
{[\mathrm{mm}]}\end{array}$ & $\begin{array}{c}\mathrm{BD} \\
{\left[\mathrm{kg} / \mathrm{m}^{3}\right.} \\
]\end{array}$ & $\begin{array}{c}\text { Workability } \\
\text { evaluation }\end{array}$ \\
\hline $100 \mathrm{R}$ & $1: 3$ & $1: 3$ & $1: 5.5$ & $1: 5.5$ & 1,17 & 119 & 1483 & Too dry \\
\hline $100 \mathrm{R}(>\mathrm{W} / \mathrm{B})$ & $1: 3$ & $1: 3$ & $1: 5.5$ & $1: 5.5$ & 1,23 & 149 & 1502 & Good \\
\hline $10 \mathrm{G}+90 \mathrm{R}$ & $1: 3$ & $1: 0.3+2.7$ & $1: 5.5$ & $1: 1.1+4.4$ & 1,17 & 163 & 1505 & Good \\
\hline $10 \mathrm{G}+80 \mathrm{R}+10 \mathrm{Fl}$ & $1: 3$ & $1: 0.3+2.4+0.3$ & $1: 5.4$ & $1: 0.6+4.4+0.4$ & 1,11 & 156 & 1510 & $\begin{array}{l}\text { Very good } \\
\text { Too much }\end{array}$ \\
\hline $15 \mathrm{G}+65 \mathrm{R}+20 \mathrm{Fl}$ & $1: 3$ & $1: 0.45+1.95+0.6$ & $1: 5.2$ & $1: 0.8+3.6+0.8$ & 1,10 & 188 & 1556 & water \\
\hline $15 \mathrm{G}+70 \mathrm{R}+15 \mathrm{Fl}$ & $1: 3$ & $1: 0.45+2.1+0.45$ & $1: 5.3$ & $1: 0.8+3.9+0.6$ & 1,04 & 158 & 1529 & Very good \\
\hline $15 \mathrm{G}+70 \mathrm{R}+15 \mathrm{Fl}(+0,5 \mathrm{SP})$ & $1: 3$ & $1: 0.45+2.1+0.45$ & $1: 5.3$ & $1: 0.8+3.9+0.6$ & 0,90 & 137 & 1496 & Dry \\
\hline $17 \mathrm{G}+67 \mathrm{R}+17 \mathrm{Fl}$ & $1: 3$ & $1: 0.5+2+0,5$ & $1: 5.3$ & $1: 0.9+3.7+0.7$ & 1,04 & 180 & 1532 & Very good \\
\hline $17 \mathrm{G}+67 \mathrm{R}+17 \mathrm{CP}$ & $1: 3$ & $1: 0.5+2+0.5$ & $1: 5.3$ & $1: 0.9+3.7$ & 1,04 & 180 & 1535 & Very good \\
\hline $83 \mathrm{R}+17 \mathrm{Fl}$ & $1: 3$ & $1: 2.5+0.5$ & $1: 5.3$ & $1: 4.6+0.7$ & 1,04 & 155 & 1526 & Good \\
\hline $25 \mathrm{G} 2+37.5 \mathrm{M}+37.5 \mathrm{~F}$ & $1: 3$ & $1: 0.75+1.12+1.12$ & $1: 5$ & $1: 1.3+1.9+1.8$ & 1,05 & 168 & 1516 & Low fines \\
\hline
\end{tabular}
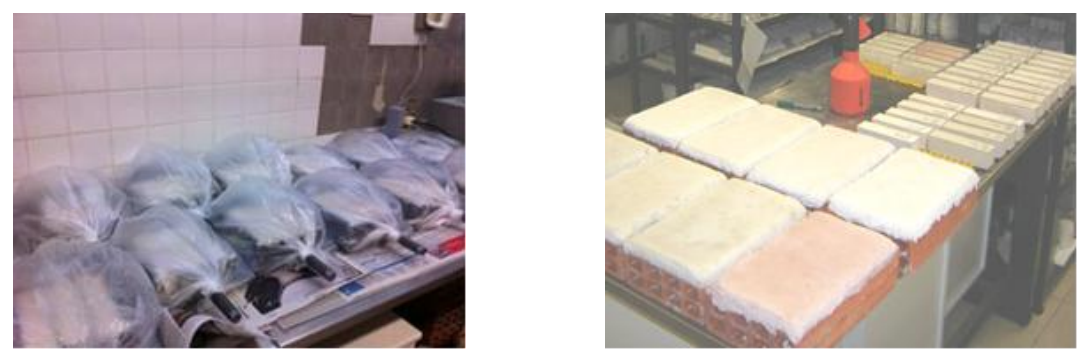

Figure 2: Prismatic samples inside the moulds and conditioned in polyethylene bags and at laboratory controlled conditions; mortar over brick samples at laboratory controlled conditions. 


\section{Characterization of the harden mortars}

Mortars behaviour was characterized at the age of 28 days for dynamic modulus of elasticity, flexural and compressive strength, open porosity, capillary absorption and drying with prismatic samples kept on curing conditions $\mathrm{N}$ and $\mathrm{A}$. Mortars behaviour was also characterized by visual observation, thermal conductivity, water intake under low pressure with Karsten tubes and mercury intrusion porosimetry (MIP) on the samples over bricks at the same age (curing condition A).

Dynamic modulus of elasticity was determined with a Zeus Resonance Meter based on EN 14146 (2004). Flexural and compressive strengths were determined based on EN 1015-11 (CEN 1999). Open porosity was determined by hydrostatic method based on EN 1936 (CEN 2006) for specimens from prismatic samples and, for specimens from samples applied over the bricks, by mercury porosimetry, based on specifications referred by Rato (2006). Capillary absorption was determined based on EN 101518 (CEN 2002) and EN 15801 (CEN 2009); capillary coefficient, that expresses the initial absorption rate, and asymptotic value, that corresponds to the maximum absorption of the samples, were determined. Drying capacity was determined following RILEM specification (1980) and Italian standard Normal 29/88 (1991); the drying rate, that represents the initial drying capability, was determined as the slope of the initial section of the drying curve, and the drying index, that represents the difficulty to achieve a total drying, was determined following a simplification of eq. 1 (Normal 1991), expressed in eq. 2. The drying index was determined over a period of 600 hours of test.

$$
\begin{gathered}
D I=\frac{\int_{0}^{t} w_{(t)} d t}{W_{\max } \cdot t} \\
D I=\frac{\sum_{i=1}^{n}\left[\left(t_{i}-t_{i-1}\right) \cdot\left(\frac{w_{t_{i-1}}+w_{t_{i}}}{2}\right)\right]}{W_{\max } \cdot t}
\end{gathered}
$$

Visual observation of the mortars over brick did not present shrinkage; nevertheless the sample dimension was only $600 \mathrm{~cm}^{2}$ (the $30 \times 20 \mathrm{~cm}^{2}$ surface of the bricks). Water absorption by Karsten tubes was determined by RILEM specification (1980) and presented in terms of absorption coefficient after 60 minutes of contact with water. Thermal conductivity was determined with ISOMET Heat Transfer equipment, with a contact probe with $6 \mathrm{~cm}$ diameter (Figure 3).

Mean values and standard deviation of dynamic modulus of elasticity, flexural and compressive strength and open porosity by hydrostatic method are presented in Table 3, for prismatic samples with curing $\mathrm{N}$ and $\mathrm{A}$.

Mean values and standard deviation of capillary coefficient, capillary asymptotic value, drying rate and drying index are presented in Table 4, for prismatic samples with curing $\mathrm{N}$ and $\mathrm{A}$.

The curves from MIP for samples of mortars applied over bricks with curing A are presented in Figure 3. Mean values and standard deviation of thermal conductivity and of water absorption by Karsten tubes, results of open porosity by mercury intrusion and the most representative pore size of the mortars are presented in Table 5, for samples of mortar applied over bricks with curing A.
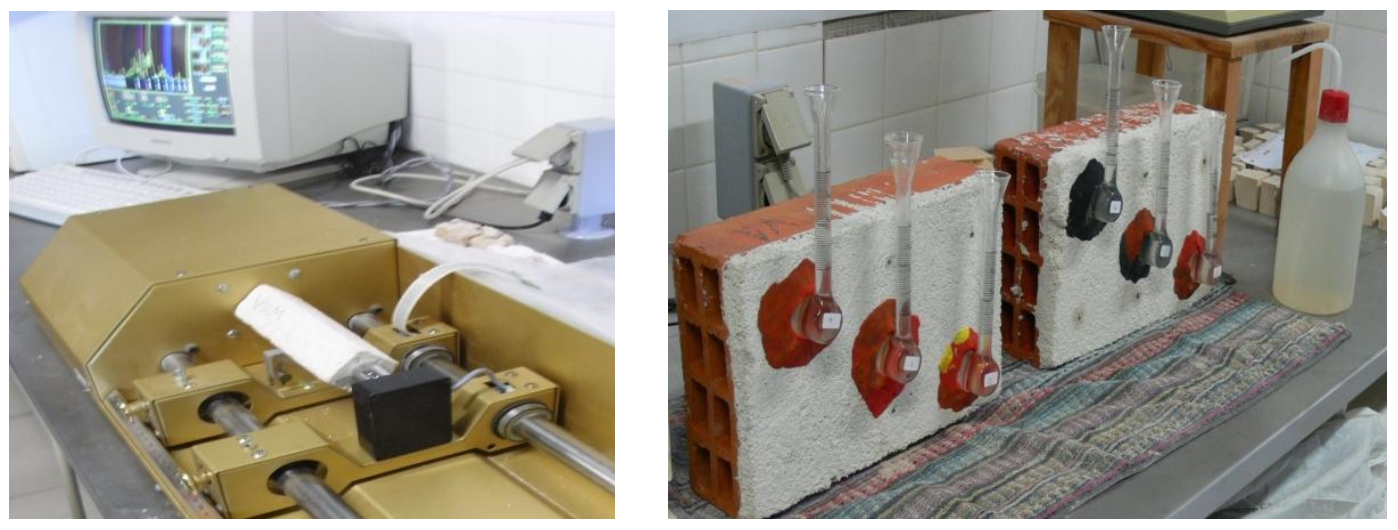

Figure 3: Tests of dynamic modulus of elasticity and Karsten tubes. 
Table 3: Dynamic modulus of elasticity (Ed), flexural (FSt) and compressive (CSt) strength, open porosity by hydrostatic method $\left(\mathrm{P}_{\text {hydr }}\right)$ - mean value and standard deviation.

\begin{tabular}{|c|c|c|c|c|c|c|c|c|c|}
\hline \multirow{2}{*}{ Mortar } & \multirow{2}{*}{ Sample/Curing } & \multicolumn{2}{|c|}{$\mathrm{Ed}\left[\mathrm{N} / \mathrm{mm}^{2}\right]$} & \multicolumn{2}{|c|}{$\mathrm{FSt}\left[\mathrm{N} / \mathrm{mm}^{2}\right]$} & \multicolumn{2}{|c|}{$\mathrm{CSt}\left[\mathrm{N} / \mathrm{mm}^{2}\right]$} & \multicolumn{2}{|c|}{$\mathrm{P}_{\text {hydr }}[\%]$} \\
\hline & & Mean & Stdv & Mean & Stdv & Mean & Stdv & Mean & Stdv \\
\hline $100 \mathrm{R}$ & \multirow{11}{*}{ 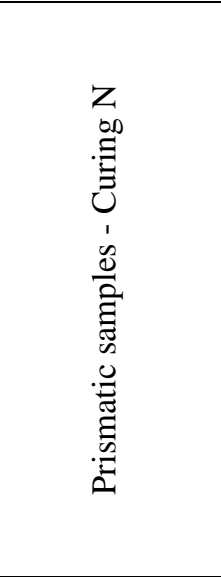 } & 3098 & 101 & 0,41 & 0,06 & 0,94 & 0,01 & 26 & 0,3 \\
\hline $100 \mathrm{R}(>\mathrm{W} / \mathrm{B})$ & & 3541 & 54 & 0,70 & 0,07 & 0,70 & 0,08 & 25 & 0,1 \\
\hline $10 \mathrm{G}+90 \mathrm{R}$ & & 3052 & 42 & 0,39 & 0,03 & 0,82 & 0,07 & 27 & 0,1 \\
\hline $10 \mathrm{G}+80 \mathrm{R}+10 \mathrm{Fl}$ & & 3890 & 36 & 0,55 & 0,06 & 0,86 & 0,59 & 26 & 0,1 \\
\hline $15 \mathrm{G}+65 \mathrm{R}+20 \mathrm{Fl}$ & & 4007 & 78 & 0,58 & 0,03 & 1,38 & 0,06 & 27 & 0,1 \\
\hline $15 \mathrm{R}+70 \mathrm{R}+15 \mathrm{Fl}$ & & 4219 & 201 & 0,61 & 0,06 & 1,57 & 0,09 & 25 & 0,3 \\
\hline $15 \mathrm{G}+70 \mathrm{R}+15 \mathrm{Fl}(+0.5 \mathrm{SP})$ & & 4927 & 178 & 0,66 & 0,07 & 2,03 & 0,21 & 23 & 0,3 \\
\hline $17 \mathrm{G}+67 \mathrm{R}+17 \mathrm{Fl}$ & & 3760 & 77 & 0,73 & 0,09 & 1,46 & 0,14 & 25 & 0,2 \\
\hline $17 \mathrm{G}+67 \mathrm{R}+17 \mathrm{CP}$ & & 3680 & 40 & 0,72 & 0,15 & 1,75 & 0,07 & 26 & 0,1 \\
\hline $83 \mathrm{R}+17 \mathrm{Fl}$ & & 3153 & 101 & 0,68 & 0,05 & 0,83 & 0,04 & 25 & 0,8 \\
\hline $25 \mathrm{G} 2+37.5 \mathrm{M}+37.5 \mathrm{~F}$ & & 3548 & 43 & 0,42 & 0,04 & 1,00 & 0,10 & 27 & 0,5 \\
\hline $100 \mathrm{R}$ & \multirow{11}{*}{ 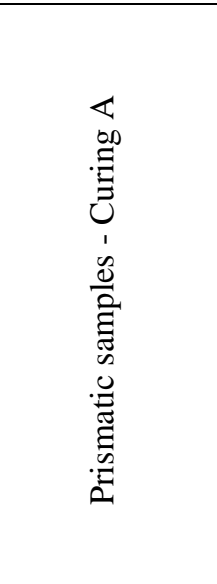 } & 2777 & 52 & 0,44 & 0,03 & 0,89 & 0,03 & 25 & 0,1 \\
\hline $100 \mathrm{R}(>\mathrm{W} / \mathrm{B})$ & & 3518 & 42 & 0,76 & 0,10 & 0,75 & 0,04 & 25 & 0,4 \\
\hline $10 \mathrm{G}+90 \mathrm{R}$ & & 3465 & 56 & 0,49 & 0,05 & 0,88 & 0,02 & 24 & 0,4 \\
\hline $10 \mathrm{G}+80 \mathrm{R}+10 \mathrm{Fl}$ & & 3925 & 125 & 0,64 & 0,05 & 1,16 & 0,10 & 24 & 0,4 \\
\hline $15 \mathrm{G}+65 \mathrm{R}+20 \mathrm{Fl}$ & & 4461 & 39 & 0,74 & 0,02 & 1,34 & 0,18 & 25 & 0,2 \\
\hline $15 \mathrm{R}+70 \mathrm{R}+15 \mathrm{Fl}$ & & 4854 & 222 & 0,78 & 0,01 & 1,41 & 0,28 & 24 & 0,2 \\
\hline $15 \mathrm{G}+70 \mathrm{R}+15 \mathrm{Fl}(+0.5 \mathrm{SP})$ & & & & & & & & & \\
\hline $17 \mathrm{G}+67 \mathrm{R}+17 \mathrm{Fl}$ & & 3699 & 46 & 0,76 & 0,06 & 1,33 & 0,06 & 24 & 0,6 \\
\hline $17 \mathrm{G}+67 \mathrm{R}+17 \mathrm{CP}$ & & 3286 & 67 & 0,73 & 0,10 & 1,37 & 0,14 & 24 & 0,2 \\
\hline $83 \mathrm{R}+17 \mathrm{Fl}$ & & 3421 & 61 & 0,62 & 0,11 & 1,16 & 0,07 & 24 & 0,4 \\
\hline $25 \mathrm{G} 2+37.5 \mathrm{M}+37.5 \mathrm{~F}$ & & 3841 & 165 & 0,56 & 0,01 & 1,11 & 0,02 & 23 & 0,4 \\
\hline
\end{tabular}

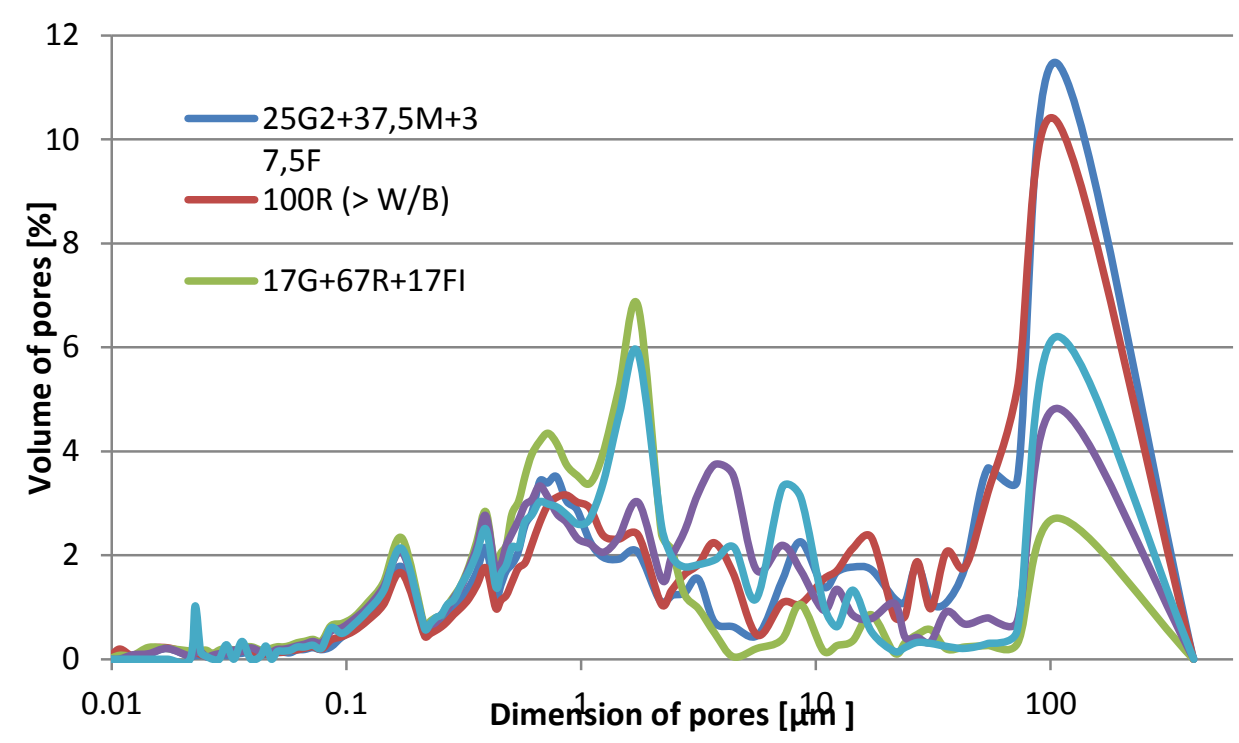

Figure 3: Mercury porosimetry curves of mortars applied on bricks after 28 days of curing with initial water spray. 
Table 4: Capillary coefficient (CC), capillary asymptotic value (CAV), drying rate (DR) and drying index (DI) - mean value and standard deviation.

\begin{tabular}{|c|c|c|c|c|c|c|c|c|c|}
\hline \multirow{2}{*}{ Mortar } & \multirow{2}{*}{$\begin{array}{c}\text { Sample/ } \\
\text { Curing }\end{array}$} & \multicolumn{2}{|c|}{$\mathrm{CC}\left[\mathrm{kg} /\left(\mathrm{m}^{2} \cdot \mathrm{min}^{0,5}\right)\right]$} & \multicolumn{2}{|c|}{$\mathrm{CAV}\left[\mathrm{kg} / \mathrm{m}^{2}\right]$} & \multicolumn{2}{|c|}{$\mathrm{DR}\left[\mathrm{kg} /\left(\mathrm{m}^{2} \cdot \mathrm{h}\right)\right]$} & \multicolumn{2}{|c|}{ DI [-] } \\
\hline & & Mean & Stdv & Mean & Stdv & Mean & Stdv & Mean & Stdv \\
\hline 100R & \multirow{11}{*}{ 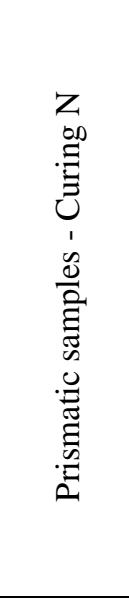 } & 3,01 & 0,12 & 19,6 & 1,6 & 3,09 & 0,14 & 0,25 & 0,03 \\
\hline $100 \mathrm{R}(>\mathrm{W} / \mathrm{B})$ & & 3,00 & 0,14 & 21,3 & 0,4 & 3,22 & 0,05 & 0,31 & 0,00 \\
\hline $10 \mathrm{G}+90 \mathrm{R}$ & & 3,65 & 0,20 & 21,5 & 0,5 & 2,85 & 0,23 & 0,26 & 0,01 \\
\hline $10 \mathrm{G}+80 \mathrm{R}+10 \mathrm{Fl}$ & & 3,06 & 0,14 & 20,1 & 0,6 & 3,13 & 0,15 & 0,28 & 0,01 \\
\hline $15 \mathrm{G}+65 \mathrm{R}+20 \mathrm{Fl}$ & & 2,91 & 0,23 & 21,6 & 1,5 & 3,08 & 0,32 & 0,31 & 0,02 \\
\hline $15 \mathrm{R}+70 \mathrm{R}+15 \mathrm{Fl}$ & & 2,81 & 0,12 & 21,0 & 1,8 & 3,14 & 0,18 & 0,31 & 0,02 \\
\hline $\begin{array}{c}15 \mathrm{G}+70 \mathrm{R}+15 \mathrm{Fl}(+0.5 \\
\mathrm{SP})\end{array}$ & & 2,12 & 0,14 & 19,1 & 2,6 & 3,04 & 0,10 & 0,30 & 0,03 \\
\hline $17 \mathrm{G}+67 \mathrm{R}+17 \mathrm{Fl}$ & & 2,55 & 0,10 & 20,3 & 0,5 & 3,24 & 0,14 & 0,25 & 0,01 \\
\hline $17 \mathrm{G}+67 \mathrm{R}+17 \mathrm{CP}$ & & 3,18 & 0,11 & 20,3 & 1,1 & 4,12 & 0,46 & 0,38 & 0,04 \\
\hline $83 \mathrm{R}+17 \mathrm{Fl}$ & & 2,50 & 0,07 & 19,8 & 1,0 & 3,61 & 0,10 & 0,34 & 0,03 \\
\hline $25 \mathrm{G} 2+37.5 \mathrm{M}+37.5 \mathrm{~F}$ & & 3,59 & 0,05 & 21,5 & 1,6 & 3,45 & 0,38 & 0,30 & 0,00 \\
\hline $100 \mathrm{R}$ & \multirow{10}{*}{ 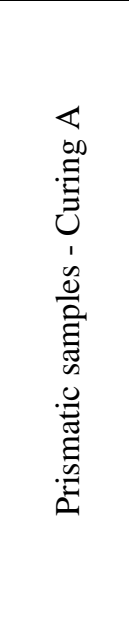 } & 2,58 & 0,11 & 18,7 & 0,5 & 3,17 & 0,52 & 0,24 & 0,03 \\
\hline $100 \mathrm{R}(>\mathrm{W} / \mathrm{B})$ & & 2,78 & 0,13 & 19,4 & 1,6 & 3,77 & 0,07 & 0,33 & 0,02 \\
\hline $10 \mathrm{G}+90 \mathrm{R}$ & & 2,86 & 0,21 & 18,6 & 0,9 & 3,03 & 0,39 & 0,25 & 0,02 \\
\hline $10 \mathrm{G}+80 \mathrm{R}+10 \mathrm{Fl}$ & & 2,40 & 0,25 & 18,8 & 0,7 & 2,77 & 0,15 & 0,25 & 0,02 \\
\hline $15 \mathrm{G}+65 \mathrm{R}+20 \mathrm{Fl}$ & & 2,57 & 0,17 & 19,4 & 0,2 & 3,14 & 0,19 & 0,29 & 0,02 \\
\hline $\begin{array}{c}15 \mathrm{R}+70 \mathrm{R}+15 \mathrm{Fl} \\
15 \mathrm{G}+70 \mathrm{R}+15 \mathrm{Fl}(+0.5 \\
\mathrm{SP})\end{array}$ & & 2,86 & 0,21 & 18,6 & 0,9 & 2,94 & 0,24 & 0,28 & 0,00 \\
\hline $17 \mathrm{G}+67 \mathrm{R}+17 \mathrm{Fl}$ & & 2,34 & 0,08 & 19,4 & 0,2 & 3,85 & 0,06 & 0,36 & 0,02 \\
\hline $17 \mathrm{G}+67 \mathrm{R}+17 \mathrm{CP}$ & & 2,49 & 0,03 & 19,2 & 1,1 & 4,02 & 0,06 & 0,38 & 0,01 \\
\hline $83 \mathrm{R}+17 \mathrm{Fl}$ & & 2,34 & 0,15 & 18,9 & 0,4 & 3,71 & 0,07 & 0,36 & 0,02 \\
\hline $25 \mathrm{G} 2+37.5 \mathrm{M}+37.5 \mathrm{~F}$ & & 3,06 & 0,38 & 19,2 & 1,7 & 3,33 & 0,24 & 0,30 & 0,01 \\
\hline
\end{tabular}

Table 5: Thermal conductivity (ThC), water absorption by Karsten tubes (AKt) - mean value and standard deviation -, open porosity by mercury intrusion $\left(\mathrm{P}_{\mathrm{MIP}}\right)$ and pore size.

\begin{tabular}{ccccccc}
\hline \multirow{2}{*}{ Mortar } & \multicolumn{2}{c}{ ThC $[\mathrm{W} /(\mathrm{m} . \mathrm{K})]$} & \multicolumn{2}{c}{$\mathrm{AKt}\left[\mathrm{kg} /\left(\mathrm{m}^{2} \cdot \mathrm{min}^{0,5}\right)\right]$} & $\mathrm{P}_{\text {MIP }}$ & $\begin{array}{c}\text { Pore size } \\
\end{array}$ \\
& Mean & Stdv & Mean & Stdv & {$[\%]$} & {$[\mu \mathrm{m}]$} \\
\hline $100 \mathrm{R}(>\mathrm{W} / \mathrm{B})$ & 0,57 & 0,08 & 7,90 & 0,57 & 29 & 100 \\
$17 \mathrm{G}+67 \mathrm{R}+17 \mathrm{Fl}$ & 0,86 & 0,09 & 5,69 & 0,50 & 22 & 2 \\
$17 \mathrm{G}+67 \mathrm{R}+17 \mathrm{CP}$ & 0,83 & 0,09 & 5,60 & 0,63 & 23 & 2 and 100 \\
$83 \mathrm{R}+17 \mathrm{Fl}$ & 0,78 & 0,08 & 6,88 & 0,81 & 24 & 100 and 4 \\
$25 \mathrm{G} 2+37.5 \mathrm{M}+37.5 \mathrm{~F}$ & 0,76 & 0,17 & 4,31 & 0,40 & 21 & 100 \\
\hline
\end{tabular}

\section{Discussion}

Except the 100R mortar, all the mortars had workability to be applied as repair mortars, with mean value of consistency of $163 \pm 15 \mathrm{~mm}$. Those mortars correspond to water/binder ratios of 1,2 to 0,9 . The mortars tested on brick had $\mathrm{W} / \mathrm{B}=1.0$, except the $100 \mathrm{R}(>\mathrm{W} / \mathrm{B})$ with 1,2 . Fresh mortars with similar composition only changing between the use of filler or ceramic powder registered the same consistency 
and bulk density. The substitution of some coarser sand by river sand reduced the consistency and the bulk density of $83 \mathrm{R}+17 \mathrm{Fl}$ mortar. For the mixture without fines $(10 \mathrm{G}+90 \mathrm{R})$ a decrease on bulk density was registered, although presenting an intermediate consistency. The fresh mortar evaluated with too much water $(15 \mathrm{G}+65 \mathrm{R}+20 \mathrm{Fl})$ presented the highest bulk density.

The mortars with higher flexural strength were generally the ones which had mixtures of coarser, river and filler or ceramic powder; nevertheless the mortar only with river sand but with not so low consistency also presented a high flexural strength. Results of dynamic modulus of elasticity and compressive strength presented a similar tendency. Mortars with higher compressive strength was the mortar with superplasticizer and the ones with mixtures of aggregates $\mathrm{G}, \mathrm{R}$ and $\mathrm{Fl}$ or $\mathrm{CP}$, with these last ones in higher amounts $(15,17$ or $20 \%)$. The mortar with the lowest compressive strength was the one only with river sand $(>\mathrm{W} / \mathrm{B})$ which presented the highest flexural strength. This mortar also presented one of the highest open porosities, which can justify this low result of compression and show that its influence for flexural is not the same. The mortar with superplasticizer, with the higher compressive strength for curing $\mathrm{N}$ also presented the lower open porosity. Generally there is not a big difference for mechanical properties between the two curing conditions and the mortars tested with MIP presented the same tendency in terms of open porosity. The open porosity by MIP is in agreement with the thermal conductivity, which as expected is lower for mortars with higher porosity.

The MIP curves evidenced clearly the differences in microstructure of mortars with the same binder:aggregate ratio when the proportions of the different aggregates and particularly the type of aggregates changed. Those differences can explain the mechanical and physical properties of the mortars.

For properties of the mortars related with water (absorption and drying) a tendency for a better behaviour is registered with curing conditions with initial water spray. The use of a superplasticizer reduced the capillary coefficient and the capillary asymptotic value but had no significant influence on the drying capacity. The use of higher water/binder ratio increased the CC and the CAV but turned faster the initial drying, although showed no benefit to complete drying capacity. Mortar without filler or ceramic powder $(10 \mathrm{G}+90 \mathrm{R}$ and $25 \mathrm{G} 2+37.5 \mathrm{M}+37.5 \mathrm{~F})$ presented the higher $\mathrm{CC}$, although not so high CAV. The drying behaviour of the mortars without filler or ceramic powder was not distinguished from the others.

The mortars chosen to be tested over the bricks presented the faster initial drying but more difficulty to achieve complete drying. In terms of water absorption coefficient by Karsten tubes after 60 minutes, the tendency of the mortars has direct correspondence with the open porosity by MIP.

The mortars analysed in this paper with type A curing (initial water spray) presented similar CC, CAV and DI values to those of air lime-based mortars with aggregates similar to $25 \mathrm{G} 2+37.5 \mathrm{M}+37.5 \mathrm{~F}$ and binder aggregate proportion 1:3 (Faria 2012b); they also registered much lower values of CC and CAV when compared to similar mortars but with a former NHL5 (in agreement with the previous version of standard EN 459-1) (Faria 2012a), what must be enhanced.

\section{Conclusions}

Dynamic modulus of elasticity between $2800-5000 \mathrm{~N} / \mathrm{mm}^{2}$, flexural strength between $0,4-0,8 \mathrm{~N} / \mathrm{mm}^{2}$ and compressive strength between $0,7-2,0 \mathrm{~N} / \mathrm{mm}^{2}$ induce a proper mechanical behaviour for application in historic masonry repair (Veiga 2010) of NHL3.5 mortars with binder:aggregate proportion 1:3 and different aggregates. Water absorption and drying behaviour of these mortars seems to be enhanced by spraying water during the initial drying.

For both mechanical and physical characteristics the use of superplasticizers should be further studied.

The use of fine aggregates, and namely of calcareous filler or ceramic powder, byproducts of gravel production and of ceramic industries, seems to be advantageous, particularly in terms of water absorption and drying capability.

The results induce that these types of NHL3.5 mortars are mechanically, physically and ecologically adequate to be applied for old masonries conservation and repair.

Further studies are being carried out to evaluate the steadiness qualities of the NHL and the durability of mortars 


\section{Acknowledgments}

The authors would like to thank the FCT-Fundação para a Ciência e Tecnologia for its support through projects METACAL (PTDC/ECM/100431/2008) and Incorporation of ceramic residues in repair mortars (EXPL/ECM-COM/0928/2012), to company MONUMENTA for the demand for starting this study about the influence of aggregates and to company Secil for the NHL3.5 and its chemical characterization.

\section{References}

CEN (2010), EN 459-1:2010 - Building lime. Part 1: Definitions, specifications and conformity criteria. CEN (2001), EN 459-1:2001 - Building lime. Part 1: Definitions, specifications and conformity criteria.

CEN (1999), EN 1015-3:1999/A1:2004/A2:2006) - Methods of test for mortar for masonry. Part 3: Determination of consistence of fresh mortar (by flow table).

CEN (1998), EN 1015-6:1998/A1:2006 - Methods of test for mortar for masonry. Part 6: Determination of bulk density of fresh mortar.

CEN (1999), EN 1015-11:1999/A1:2006 - Methods of test for mortar for masonry. Part 11: Determination of flexural and compressive strength of hardened mortar.

CEN (2002), EN 1015-18:2002 - Methods of test for mortar for masonry. Part 18: Determination of water absorption coefficient due to capillary action of hardened mortar.

CEN (2006), EN 1936:2006 - Natural stone test methods. Determination of real density and apparent density, and of total and open porosity.

CEN (2004), EN 14146:2004 - Natural stone test methods. Determination of the dynamic modulus of elasticity (by measuring the fundamental resonance frequency).

CEN (2009), EN 15801:2009 - Conservation of cultural property. Test methods. Determination of water absorption by capillarity.

Charola, E. et al. (2005), Pozzolanic components in lime mortars: correlating behaviour, composition and microstructure. Restoration of Buildings and Monuments, 11 (2),111-118.

CNR - ICR (1991), Normal 29/88. Misura della perdita per evaporazione dell'acqua assorbita dal materiale, Italia.

Faria, P. et al. (2012a), Compatible natural hydraulic lime mortars for historic masonries (in Portuguese). In CIRea2012 - International Conference Rehabilitation of Old Masonries, NOVA University of Lisbon, 29-38.

Faria, P. et al. (2012b), Lime-based mortars for ceramic tile application: the influence of the lime, the use of a metakaolin and the curing. Intern.Conference AZULEJAR, Aveiro University (CD).

Grilo, J. (2013), Characterization of Portuguese NHL3.5 based mortars (in Portuguese), MSc thesis, Faculty of Sciences and Technology, NOVA University of Lisbon.

Rato, V. (2006). Influence of morphologic microstructure on mortars behaviour (in Portuguese). PhD thesis, NOVA University of Lisbon.

RILEM (1980), Commission 25 PEM, Test no II.4 - Water absorption under low pressure; Test $n^{\circ}$ II.5 Evaporation curve. Materials \& Structures 13 (75), 200-207.

Veiga, R. et al. (2010), Lime-based mortars: viability for use as substitution renders in historical buildings. Architectural Heritage 4 (2), 2010, 177-195. 